First Peoples Child \& Family Review

An Interdisciplinary Journal Honouring the Voices, Perspectives, and Knowledges of First Peoples through Research, Critical Analyses, Stories, Standpoints and Media Reviews

\title{
Developing a Culturally Restorative Approach to Aboriginal Child and Youth Development: Transitions to Adulthood
}

\section{Estelle Simard and Shannon Blight}

Volume 6, Number 1, 2011

URI: https://id.erudit.org/iderudit/1068895ar

DOI: https://doi.org/10.7202/1068895ar

See table of contents

Publisher(s)

First Nations Child and Family Caring Society of Canada

ISSN

1708-489X (print)

2293-6610 (digital)

Explore this journal

Cite this article

Simard, E. \& Blight, S. (2011). Developing a Culturally Restorative Approach to Aboriginal Child and Youth Development: Transitions to Adulthood. First Peoples Child \& Family Review, 6(1), 28-55. https://doi.org/10.7202/1068895ar
Article abstract

An innovative approach to providing "care" to Aboriginal child who are making a transition into adulthood embodies the concept of culturally restorative practice. This paper is a literature review on Aboriginal child development for children and youth transitioning from a youth to an adult. This paper contains excerpts from "Developing a Culturally Restorative Approach to Aboriginal Child and Youth Development: Transitions to Adulthood" published as a social policy paper for Ontario's Ministry of Child and Youth Services. The paper was a review of the literature of the following: culturally restorative practices, best practices for successful engagement with Aboriginal populations, thematic of Aboriginal development, as well as implications for child and youth services.
Copyright (C Estelle Simard, Shannon Blight, 2011
This document is protected by copyright law. Use of the services of Érudit (including reproduction) is subject to its terms and conditions, which can be viewed online.

https://apropos.erudit.org/en/users/policy-on-use 


\title{
First Peoples Child \& Family Review
}

An Interdisciplinary Journal Honoring the Voices, Perspectives and Knowledges of First Peoples through Research, Critical Analyses, Stories, Standpoints and Media Reviews

Volume 6, Number 1, 2011, pp. 28-55

\section{Developing a Culturally Restorative Approach to Aboriginal Child and Youth Development: Transitions to Adulthood}

\author{
Estelle Simard ${ }^{\mathrm{a}}$ and Shannon Blight ${ }^{\mathrm{b}}$
}

\begin{abstract}
a Estelle Simard is from the Anishinaabe Nation and a member of Couchiching First Nation. She is the Executive Director of the Institute for Culturally Restorative Practices. Much of Estelle's experience was in the culturally competent management of integrated children's mental health and child welfare services. She has direct supervisory and clinical services expertise with Aboriginal people and has specialized in family preservation strategies by incorporating cultural activities into service practice. In addition, Estelle has presented at national and international forums on child welfare on "cultural attachment theory."

b Shannon Blight is currently employed at Weechi-it-te-win Family Services in Fort Frances, Ontario as the Clinical Team Leader. She received her Master of Social Work degree from the University of Minnesota, Duluth; prior to that she graduated from Carleton University with an HBSW in 2003 Shannon has over 15 year experience in the areas of chemical dependency and child welfare. Her experience in child welfare has been within the mental health spectrum as well as child protection. Shannon is strong believer that personal wellness is essential to becoming an effective leader, manager or direct practitioner. Her personal practice model is grounded in Anishinaabe teachings that promote the empowerment of natural resiliency factors within individuals, families, and communities.
\end{abstract}

Questions or correspondence concerning this article may be addressed to:

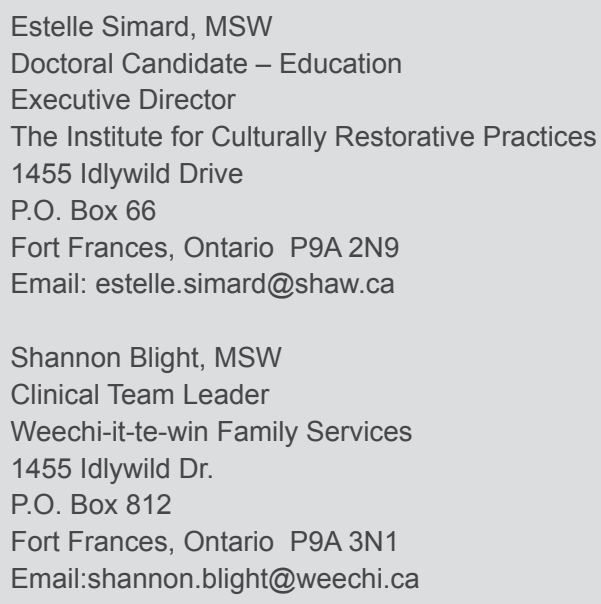

\begin{abstract}
An innovative approach to providing "care" to Aboriginal child who are making a transition into adulthood embodies the concept of culturally restorative practice. This paper is a literature review on Aboriginal child development for children and youth transitioning from a youth to an adult. This paper contains excerpts from "Developing a Culturally Restorative Approach to Aboriginal Child and Youth Development: Transitions to Adulthood" published as a social policy paper for Ontario's Ministry of Child and Youth Services. The paper was a review of the literature of the following: culturally restorative practices, best practices for successful engagement with Aboriginal populations, thematic of Aboriginal development, as well as implications for child and youth services.
\end{abstract}

Key words: Aboriginal child development; Aboriginal developmental theory.

\section{Methodology}

\section{Indigenous Ways of Knowing}

The purpose of this paper is to provide an Indigenous perspective on development ${ }^{1}$. The literature review was in a manner conducive to Indigenous/Aboriginal ways of knowing. Indigenous/Aboriginal ways of knowing presently are contributing to a broad spectrum of academic knowledge (Absolon, 2010; Cochran, Marshall,

\footnotetext{
1 Although the authors would have liked to use the word "Indigenous" throughout the paper, the term Aboriginal will be used in replace of it. Aboriginal peoples refer to First Nation, Métis, Status, Eligible for Status, or Inuit people of Canada.
} 
Garcia-Downing, Kendall, McCubblin, \& Gover, 2008; \& Tuhiwai-Smith, 2002). Indigenous/ Aboriginal ways of knowing as described in the literature is the traditional knowledge transmitted from one generation to the next (Simpson, 2004). This body of knowledge is wholistic, family and community oriented, with an understanding of ancestral knowledge (Simpson, 2004). TuhiwaiSmith (2002) has found that Indigenous research methodologies and designs have produced better outcomes for Indigenous people, and it is with this intention in mind that the perspectives on development are noted.

As a part of an Indigenous research design, 'celebrating survival' has presented as the main ideological basis for this literature review and developmental structural design. Celebrating survival "accentuates not so much our (Indigenous) demise but the degree to which Indigenous peoples and communities have successfully retained cultural and spiritual values and authenticity" (Tuhiwai - Smith, 2002, p. 145). Cultural perseverance celebrates our cultural structure, our cultural attachment, and our deeply ingrained cultural teachings on development. Celebrating survival, as an Indigenous research methodology, not only acknowledges the collective soul wound as Indigenous people, but also acknowledges and celebrates the extraordinary cultural survival unique to Indigenous people (Tuhiwai - Smith, 2002). This celebration of survival is affirmed through our language, our teachings, and our cultural structure.

Cajete (1994) in Tuhiwai - Smith, (2002) stated "celebrating is a natural outcome of spiritual sharing and it too can take a diversity of forms. It is an individual and communal process that celebrates the mystery of life and the journey that each of us takes. Celebration is a way of spreading the lights around" (p. 145).

Indigenous development is presented throughout this paper in a manner that celebrates survival of Indigenous knowledge.

\section{Developing a Culturally Restorative Approach to}

\section{Aboriginal Child and Youth Development: Transitions to Adulthood}

In Aboriginal worldview, visioning is a fundamental construct in the development of identity (Gross, 2002). As a part of visioning, storytelling evolves with the purpose to transcend knowledge and bring about value-based learning (Gross, 2002). One such story will begin this process of describing child and youth development in a value-based manner. An Elder in a Northern Ontario community described his dream to the audience. He described vividly the coming of thousands upon thousands of Abinoojiiyag (children) to Turtle Island. In his vision, he spoke of the transition of elders to the spirit world, the smaller circle of elders that would remain. He spoke of the approach of the children, the happiness of their spirits, and he guarded with caution against the transmission of dysfunction on the abinoojiiyag. In his storytelling he stated,

\begin{abstract}
"do they know where they are going?... those little ones ... Maybe they don't ... but you know where they are going ... You are the ones that have to prepare that spot for them cause ... they are coming and they are coming by the thousands ... they are gonna darken the sky as they come down on this earth ... what have you got for them" (Sitting Eagle in Weechi-it-te-win Family Services, 2005).
\end{abstract}

In Aboriginal child and youth development sectors, a cultural perspective on child development is an important strategy for the government of Ontario. Recently, there has been a shift in Ontario toward the culturally competent systems of care in the social work, health, and mental health spectrums (Crooks, Chiodo, \& Thomas, 2009). In a grander scale, world politics, social implications, and subsequent 
social responsibility has led to the United Nations Convention on the Rights of the Child. Within the Convention on the Rights of the Child under Section Eight - the child's entitled to the preservation of his or her identity (Bolzman, 2009; \& Herrmann, 1991). Even with these political conventions, a colonization process has chipped away at the Aboriginal identity of children and youth. Aboriginal identity was not seen as a priority but more of a problem in the assimilation process of Aboriginal children and youth throughout the centuries. Great atrocities across Canada occurred in the vision of eradicating Aboriginal identity. One of the biggest problems that remains with the process of colonization is the deep seated unspoken history that have been passed on from generation to generation for both Aboriginal and non-Aboriginal alike. These very misconceptions and misapplications of Aboriginal understanding have lead to a continued process of colonization, which has not offered the necessary spiritual core to begin developmental achievement with confidence. The difficulty to achieving these goals is embedded in the philosophy of cultural understanding and application.

Cross cultural learning is a systematic approach, which requires learning tools for professionals in addition to a shift in philosophy within an organizational structure to create the elements of cultural safety for Aboriginal children and youth. Pedagogical practices for workers have promoted and fostered an ethnocentric view of educational development (Berrell, Gloet, 1999; Good, 2009), and as a result, there is unpreparedness for working in cross cultural settings with Aboriginal clientele. Some educational researchers have begun to lay an academic framework for understanding cultural applications in successful engagements with Aboriginal children (Berrell \& Gloet, 1999; Good, 2009; Grant and Haynes, 1995; \& Stairs and Bernhard, 2002). Stairs and Bernhard (2002) empowered traditional knowledge on child development and discussed the importance of family, community, and spirituality in wholistic development. Good (2009) discussed the importance of inclusion into a multicultural society and the importance of blending and understanding history from an Indigenous and non-Indigenous perspective. Cultural discourse involved in shifts in perspectives in educational settings was provided as a backdrop to cross cultural learning (Berrell \& Gloet, 1999). In educational settings the shift to include Aboriginal perspectives and content is afoot; however, in social service sectors in Ontario it maybe just the beginning.

It is hoped this paper will influence these systems to take another step forward in promoting culturally "relevant" interventions and approaches to service provision geared toward developmental achievement for Aboriginal youth. Thematics of Aboriginal development are seen within the context of worldview, cultural structure, cultural attachment, identity, relationship, and most important developmental achievement. Developmental achievement will present in a manner that promotes effective developmental interventions that are community driven, community-based, and culturally relevant. Selected Aboriginal developmental authors will be presented as best practice, but offer some array of options for children and youth seeking cultural developmental achievement.

\section{Cultural Restorative Practice}

Culturally Restorative Practice (CRP) is a curriculum based on the MSW research project entitled Culturally Restorative Child Welfare Practice: with a special emphasis on cultural attachment theory. Simard (2009) had worked extensively with Weechi-it-te-win Family Services, and recognized the value of practiced-based evidence, in the promotion of alternative child welfare practices. Thematics developed into valuable practice knowledge, which has become a transformational strategy for different children's initiatives. Culturally restorative practice rebuilds First Nation community structures through the active engagement of cultural research. Cultural research defines as the process of acquiring 
knowledge from the ancestral knowledge keepers within the First Nation community, and using this knowledge for the betterment of the community. Culturally restorative practices build on the sacredness of teachings and culture within an Aboriginal population by careful reflection on the natural protective network. The natural protective network is a principle of child, family, extended family, community, and Nationhood, contributing to the successful life way of the child. The natural protective network is a part of Aboriginal practice

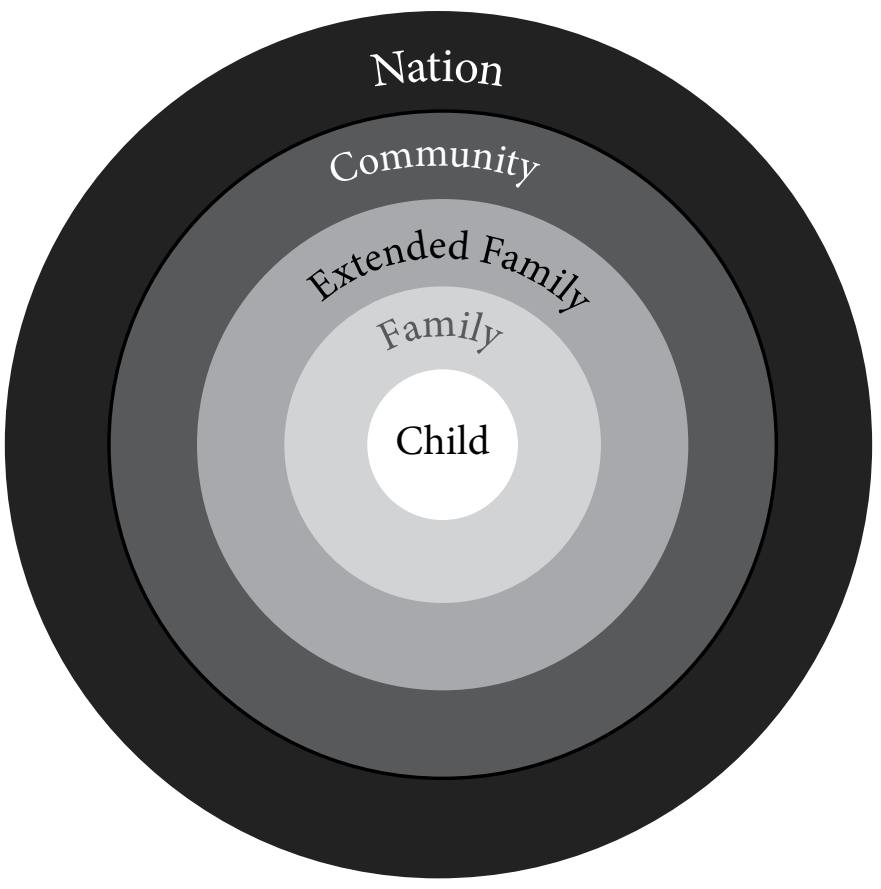

Diagram 1: The Natural Protective Network Principle Simard (2009)

models, in which all elements of society embrace the responsibility of solidifying a child's cultural identity and subsequent cultural formation into adulthood. Each member of society contributes to all children's wellbeing in this effort. The protective network principle is a foundation for cultural attachment theory as a mechanism to culturally restorative practice (Simard, 2009). (see diagram 1 above).

The theoretical learning basis for the culturally restorative practice is Aboriginal paradigms and Aboriginal constructivism. Culturally restorative practice asserts the following as it relates to cultural attachment theory:

The mechanisms of cultural attachment theory to achieve cultural restoration has suggested the greater the application of cultural attachment strategies the greater the response to cultural restoration processes within a First Nation community. This directly proportional proposition suggests an alternative strategy with First Nation people, which is based on reinvestment in cultural attachment strategies in First Nation communities (Simard, 2009, p. 54).

Culturally restorative practice incorporates cultural attachment theory as the main impetus to developmental learning (Simard, 2009).

\section{Thematic of Aboriginal Development}

Developmental psychology is a phenomenon that has etched the development of Aboriginal children for centuries. Development is the changes in human behavior that occurs throughout the lifespan, where all parts of self are evaluated against a worldview different from the Aboriginal context. Developmental theories are typically stage theories, in which you cannot pass from one stage to the next without its successful completion. Developmental theories link to nature versus nurture debates, behavioral roles in child development, information processing frameworks, or interpersonal relationships, or attachments. Developmental constructs were gathered through observational studies and established a basic milestone or transition of 'normal' development. Developmental milestones established the norm but also established the 'delay' of normal development. The milestones were often linked to age-based behavioral changes identified through habituation. Developmental stages entailed changes from prenatal, to infancy, to babyhood, to early childhood, to late childhood, to adolescence, to early adulthood, to middle age, 
to old age. Development has been evaluated in the light of emotion, intellect, moral, physical, and social domains. Each domain has influenced each other in their respective complexity. Developmental theorist empowered his or her own unique understanding of development, for example, Freud empowered his psycho-sexual stages of development, Erickson empowered his developmental theory and Jean Piaget empowered his stages of cognitive development. Each developmental theory came with their own philosophical makeup and ideas on how a child develops throughout his or her life. The literature has also evolved to show how ecological systems impact development throughout one's lifetime. All of these developmental theories are important; however, they are missing one key piece when working with the Aboriginal population - the spirit.

Applying non-Aboriginal developmental theories with Aboriginal youth exclusively will not provide a complete or exact description nor will it show positive outcomes, because it is quantified against mainstream norms. These norms do not include the socio-economic contextual factors, which influence development. The remaining portion of this paper will begin to deconstruct development from an Aboriginal perspective. Aboriginal development must been seen in the light of the context of historical significance and its consequences on present day issues. Furthermore, these present day issues must be reconciled with cultural safety efforts. The thematic of Aboriginal development starts with Aboriginal worldview, cultural structure, cultural attachment, identity development, relational development, and task achievement.

\section{Aboriginal Worldview - Aki naanaagadawaabiwi}

To understand developmental milestones for Aboriginal children and youth, it is important to establish an in-depth look at how Aboriginal people see the world. It is important to understand that through an Aboriginal lens, all things are related on a spiritual level. A primary difference between Aboriginal worldview - Aki naanaagadawaabiwi and Non-Aboriginal theories of development is that everything in Aboriginal worldview - Aki naanaagadawaabiwi is based on the spirit whereas the concept of spirituality or the spirit is often overlooked in Non-Aboriginal theories of development. Cross (2010) described worldview as a
term used to describe the collective thought process of a people or culture. Thoughts and ideas are organized into concepts. Concepts are organized into constructs and paradigms. Paradigms link together to create worldviews (p. 1).

Cross (2010) described two different types of worldviews: linear and relational. Linear worldview is systematic whereas relational worldview is cyclic. Aboriginal or Indigenous people come from a relational worldview.

... it is intuitive, non-time oriented and fluid. The balance and harmony in relationships between multiple variables, including spiritual forces, make up the core of the thought system. Every event is understood in relation to all other events regardless of time, space, or physical existence. Health exists only when things are in balance and harmony (Cross, 2010, p. 2).

In relational worldview, problems are viewed as imbalances and interventions are focused on bringing a person back to balance and harmony (Cross, 2010).

\section{Many Indigenous peoples in Canada and elsewhere refer to health and wellness as a balance between the emotional, mental, spiritual and physical dimensions of the person in connection to his or her family and community (Parlee and O'Neil, 2007).}

One of the most common means of describing Aboriginal worldview - Aki naanaagadawaabiwi is through the use of the Medicine Wheel. Hart (2002) explained one of the foundational concepts of the Medicine Wheel is "wholeness", 
which challenges a person to understand each of the four parts of the Medicine Wheel and how he or she relate to one another. The next major concept Hart (2002) expressed is balance and the idea of bringing those four elements into balance and harmony.

The Medicine Wheel can be applied to the individual, family, community, and nation. Nabigon and Mawhiney (1996) discussed Aboriginal worldview - Aki naanaagadawaabiwi extensively. Nabigon and Mawhiney (1996) explained that Aboriginal teachings are based on natural world occurrences and symbolism; furthermore, through Aboriginal worldview - Aki naanaagadawaabiwi an individual is not separate from the natural world because all things are interconnected. Nabigon and Mawhiney (1996) used the Cree Medicine Wheel to illustrate the idea of finding balance and harmony in relationship with all of Creation. Through this model there is an assumption that growth and healing is always a spiritual process based on connecting to oneself and finding balance.

Aboriginal worldview Aki naanaagadawaabiwi is closely related to the fundamental concepts of tribalism and shamanism as described by Voss, Douville, Soldier, \& Twiss (1999) in what they termed a spirit centered worldview. This means that everything within the universe is spiritual, everything has spiritual forces and these spirits have the power to influence results (Voss, et. al., 1999). This is an ancient philosophy in which humans are viewed as equals with other creatures on earth and knowing this reality requires a great deal of humility. They explain Tribalism as the high regard for interconnectedness such as kinship ties that extend from family, community, tribe; it also crosses generations and is inclusive of ancestors (Voss, et. al., 1999). Each person is viewed in a manner collective of his or her heritage and ancestry. They explain that the Lakota view life as a circular process in which there is really no beginning and no end and where both positive and negative forces exist not only across the lifespan but also within each person (Voss, et. al., 1999). It is important to note that within this spirit centered worldview, good and evil, sickness and health, are not separate but instead they are coexistent, and it is a matter of obtaining balance and finding harmony in ones' self (Voss et. al., 1999).

InAboriginalworldview-Akinaanaagadawaabiwi, the ancestors are viewed in the present tense. This concept is reflected in Weaver's (2003) discussion on cultural competence with First Nation people.

Within many Native American cultures, there is a sense of existing within a time continuum. The people of today maintain strong connections to ancestors and contemporary actions are undertaken with future generations in mind. The concept of seven generations is present in many First Nations cultures, although it is defined somewhat differently by different people. For some, the ancestors seven generations ago were planning for the people of today and these plans are the reason there is still land, language, and culture left for indigenous people. The people of today have the responsibility to ensure that the needs of future generations will be met in the same way (Weaver, in Lum, 2003, p. 203).

The ideology of seven generations promotes a sense of individual responsibility for the collective good. In Anishinaabe ${ }^{2}$ a cultural teaching exists on the concept of seven generations principles. The Anishinaabe word is niizhwaaching aanike'inawendiwin, and it reminds us that the decisions we make today will influence the next seven generations to come. Therefore, it is with great respect and caution that Aboriginal people proceed in their decision-making responsibility. The original language of each Aboriginal nation is the most powerful way to understand the worldview because in the Aboriginal nation's original language there exists meaning, teachings, at times

2 Anishinaabe refers to the Aboriginal people of the Anishinaabe Nation. Several borders have divided the Anishinaabe Nation; however, they are one Nation of people. The Anishinaabe have different names allocated to this tribe as well - Ojibway, Ojibwa, Ojibwe, Chippewa, Oji-Cree, and the Saulteaux. The Anishinaabe people have a language dialect, teachings, ceremonies, and societal practices unique to their Aboriginal tribe (Anderson, 2002). 
ceremonies, colors, and intentions. Sitting Eagle of Rousseau River, Manitoba provided a teaching on seven generations at the Rainy River First Nation Roundhouse in 2005. He discussed that today the Anishinaabe carry the pain of the past seven generations, and the healing and success that take place in this lifetime or lack thereof, will have a direct result on the next seven generations (Sitting Eagle, 2005).

\section{Ways of Knowing \\ - Anishinaabe}

\section{naanaagadawedamowinan}

Aboriginal or Indigenous people of Canada have a rich cultural make up and their knowledge systems have survived over 500 years of colonization. This cultural make-up exists in the language and sacred ceremonies of each Aboriginal Nation to various degrees. Aboriginal knowledge paradigms are unique and different from non-Aboriginal paradigms. Aboriginal knowledge is not consistent with scientific method, it cannot be measured or possessed; instead, it is the capacity of one's' being to be resourceful and find context to everything in life (McKinley, Jones, \& Maughan, 2009).

At the core of most Aboriginal knowledge systems is the building of competencies in selfdevelopment for the pursuit of sacred roles and functions within a society. Aboriginal knowledge systems are based on the natural protective network principle (Simard, 2009), in which the family, the extended family, the community, and the Nation support the child's wholistic development. Each member of society has a sacred responsibility in the sustaining of this development for a child. An example of language, ceremonies, and responsibilities exists within the word Anishinaabe naanaagadawedamowinan.

Anishinaabe naanaagadawedamowinan is an Anishinaabe word that translates as worldview, but means how Anishinaabe people come to see the world from a wholistic perspective. Anishinaabe naanaagadawedamowinan is the life teachings for a child and its purpose or root ideology is to achieving mino-biimaadiziwin. Mino-bimaadiziwin, is a word that means wellbeing of a person, and describes a sacred way of life for the Anishinaabe. Aboriginal people understand to succeed in the present-day multicultural world the child must be spiritually grounded in Mino-bimaadiziwin (Simard, 2009).

Aboriginal ways of knowing are sacred knowledge passes down from generation to generation within a Nation of people (Ball, 2004). It is an old knowledge that has been lived and ancestrally transmitted via the generations. Aboriginal knowledge is not a bounded concept; rather it is a process that reflects a set of relationships and an embodiment of one's entire life (McKinley, Jones, \& Maughan, 2009). More simply, "individuals live and enact their knowledge and, in the process, engage further in the process of coming to be - of forming a way of engaging others and the world" (McKinley, et. al., 2009, p. 2).

Within Aboriginal language, the word knowledge is considered a verb; whereas in western worldview knowledge is deemed a noun. Therefore, in Aboriginal worldview and their language, knowledge is considered a living, moving, growing entity (McKinley et. al, 2009). Because Aboriginal knowledge is considered an action, it is always placed within a value-based context. Aboriginal or "Indigenous knowledge systems value contextualized knowledge that is local and particular to the setting" (McKinley et. al, 2009 , p. 6). Aboriginal or Indigenous knowledge is value-based and intrinsically tied to sacred land site where teachings, ceremonies, stories were given or where medicines or food were gathered (Battiste, 2002).

\section{Cultural Structure - Anishinaabe zaagaswe'idiwin}

An important trajectory for Aboriginal youth development pertains to their sense of belonging within their cultural structure - Anishinaabe zaagaswe'idiwin. Cultural structure refers to the variables and processes that occur within a way 
of life, or more specifically it is all the items living and non-living that provide cultural understanding and context. A fine description of the processes that occur within culture are noted in Greenfield, Keller, Fuligni \& Maynard (2003).

We view culture as a socially interactive process of construction comprising two main components: shared activity (cultural practices) and shared meaning (cultural interpretation). Both components of cultural processes are cumulative in nature since they occur between, as well as within, generations. Meanings and activities not only accumulate by also transform over both developmental time - across a single life cycle, and historical time - between generations (Greenfield, et. al., 2003, p. 462).

Another model of cultural variables are included in Day (2006) presentation on cultural competence. These definitions have been translated into Anishinaabemowin ${ }^{3}$ and include the following variables:

1. values - ishpendaagokin;

2. language and communication patterns . azhawinamaadiwin $\left(a n^{4}\right)$;

3. family orientations - izhiningodogamig;

4. healing beliefs and practices . noojimotwaawin (an) gaye izhichigewin;

5. religion - izhitwaawin;

6. art, dance, and music - ozhichigan(an), niimi'idiwin nagamo(an);

7. diet and food - inanjigewin;

8. recreation - izhimamaajiiwin;

9. clothing - gigishkigan (an);

10. history - mewinzha;

11. social status - eshpendaagozid; and

12. social group interactions - oko'idiwin.

3 Anishinaabemowin is the original language of the Anishinaabe people. Although there are many Nations in Ontario, Canada, this paper is partially Anishinaabecentric due to choice of language used throughout the remaining portion of the paper.

4 (an) after an Anishinaabemowin word, means this is the plural version of the word.
As previously stated the original language of the people provides the teachings, ceremonies, meanings, and teaching constructs for each word. These cultural variables are presented in Anishinaabemowin, but can be easily translated into other Nation's original language thereby providing a differing perspective on the cultural variable unique to another cultural language. The process of gathering the language information is called cultural diversity in action. Helpers must remember, in order for Aboriginal children to thrive within the majority culture, they must be grounded within the structure of their own culture and therefore be attached to the cultural variables and process within their families, communities, and Nation.

At the root of the sacred tree of cultural structure are values - ishpendaagokin. All cultural variables mentioned in Day's (2006) culture model are based on values - ishpendaagokin. Other mechanisms of cultural structure such as beliefs, rituals, customs, traditions, ceremonies are also "value" based. The Anishinaabemowin for these concepts are included in the word izhitwaawin (an). For Aboriginal youth to be deprived of their cultural processes that teach values such as shared activity and shared meaning (Greenfield et al., 2003) is to deny them of their roots to identity development or to deny them their spiritual core. maaminonendamowin.

\section{Clan - Doodem}

Mother earth and the animal world are some of the teachers of Indigenous values (Nabigon and Mawhiney in Turner, 1996). Elders, family and community members teach values through stories that are about the earth, nature, the spirits, and animals. Storytelling in and of itself is a major way that values are developed within children; another method is through observation of nature and animals. Oral tradition or storytelling is a significant aspect of Aboriginal culture; essential values are transmitted during storytelling. Becoming physically close to nature is another aspect highly regarded in Aboriginal 
culture because the values are learned through a close relationship with nature. In Aboriginal culture, nature is an instrumental part of a child's upbringing. The belief that everything has a spirit is solidified by holding the natural world in high regard. Through this worldview there is a belief that everything is alive including rocks, plants, water, air and animals (Nabigon and Mawhiney in Turner, 1996) .

The clan teachings are an important part to understanding doodem connections. Doodem is the clan to which each Aboriginal child belongs, with the clan comes innate individual behavior characteristics similar to the doodem. Animals are looked at as value-based teachers. The animal world teaches life values such as kindness, honesty, respect and how to conduct oneself in relation to another (Nabigon and Mawhiney, in Turner, 1996). An example of values, beliefs, and life teachings, which transmit through the animal world lies within the conduct of the loon. The loon teaches about the love of family. Loons choose a lifetime mate, which is likely why their courting process is so public. There is a teaching that when you hear the loons calling in the evening they are celebrating a marriage. In loon life, both parents share responsibility for the children. Loons will adopt a baby loon if it is found to be abandoned or in need. The parent loons will accept that baby as their own and raise it up within his or her protective family system. There is numerous other teaching such as this within the animal world that children are provided within their cultural structure or shared activities.

Aboriginal children need to understand their customs such as the clan system; furthermore, it is in their best interest to know their clan or totem and be familiar with the inherent gifts that come with being a member of that clan. The clan system is a key organism that has provided cultural structure to the way of life for Aboriginal people for hundreds of years. The clan system is an ancient custom, which has been passed down through many generations; it is a system that has been recorded through historical rock painting, carvings, birch bark scrolls, and pictographs
(Mcguire, 2008; Sitting Eagle, 1993). Protocols exist for attaining information about clan systems. Information or knowledge on the clan system is usually given in the form of stories. It is believed that these ancient stories have a spirit that guides the learner (Mcguire, 2008; Sitting Eagle, 1993).

Although there may be variations in traditional teachings of clan systems, it is a fundamental customary structure within Ojibwe, Saulteaux, Algonquin, Oji-Cree and Iroquois culture. Mcguire (2008) notes that clan systems are primarily social systems that guide social relationships within the tribe and these social relationships and responsibilities attribute to community and tribal cohesion. A person's connection to clan provided several social relationships within the community that not only pertain to family, social responsibility, social role, but also a relationship to the land. The obligations within clan systems also served as a behavioral guide for life stages such as marriage, occupations, and social/political responsibilities.

Clan members are considered to be related through the clan system. An element of a person's identity is determined through the clan system by providing individual obligations for the collective good of the community (Mcguire, 2008). If a person does not know their clan for whatever reason there are options available for that person to determine his or her clan, either through adoption or through a spiritual ceremony. "Membership into clans is an inclusive process, although, one had to agree to take on the responsibilities associated with their adopted clans" (Mcguire, 2008, p. 2).

Sitting Eagle (1993) referred to the great law of clans as the odoidaymiwan. He describes it as a "way of sacred knowledge and order - a system that became a framework of government, for the unity, strength, and social order of the Nation" (p. 3). The seven original clans and each corresponding social function are as follows: the crane - chieftainship and leadership for external negotiations (Banai, 1981; Sitting Eagle, 1993). The loon - chieftainship for internal responsibility and effective community management, fish 
- philosophers, mediators and visionary for program planning, design and leadership (Banai, 1981; Sitting Eagle, 1993). Bear clan people are guardians, healers, historians, protectors of justice and legal issues (Banai, 1981; Sitting Eagle, 1993). Martin clan people are hunters, providers and warriors for environmental protection and economic development (Banai, 1981; Sitting Eagle, 1993). Deer or hoof clan people are reconcilers and pursuers of wellbeing for the purpose of effective communication and community and social development (Banai, 1981; Sitting Eagle, 1993). Bird clan people are spiritualists, teachers, and pursuers of knowledge, facilitators of ongoing education and survival of the people (Banai, 1981; Sitting Eagle, 1993). From these clans there are sub-clans. The leader of the fish clan is the turtle clan; other sub-clans include bullhead, sucker, rattlesnake, northern, sturgeon, and frog. The chief of the bear clan is the black bear, other sub-clans include the brown, white, grizzly, and skunk bear. The chief of the martin clan is the marten; other sub-clans include the lynx, weasel, wolf, mink, otter, beaver, and muskrat. The chief of the bird clan is the bald eagle; other sub-clans include the golden eagle, hawks, skydivers, swimmers etc. (Sitting Eagle, 1993).

\section{Language - Inwewin}

Aboriginal values are within the language. Aboriginal people who were brought up to speak their language have a different worldview, which is much deeper, spiritual, and is value-based. Those that speak Anishinaabemowin language will concur that it is essentially a "teaching" language in the sense that values and teachings are passed through the language. An explanation of this concept is because the Anishinaabe language is $80 \%$ verbs. This indicates that Anishinaabe is a fluid language in which most reference points are in action form rather than noun form (Vollum, 1994). Second, there is no differentiation between male and female; instead, a phrase remains the same whether you are referring to a man or a woman (Vollum, 1994). The Anishinaabe language is based on relationships and the language itself reflects the deep relationships that exist in this world (Vollum, 1994). For example, the word grief in English translates to a noun, which defines as deep mental anguish that arises from bereavement (Dictionary, 2011). The word grief in Anishinaabemowin is ninondemowin and translates as a healing that takes place through storytelling, this healing will occur because of this process. This example demonstrates not only a difference in language but also a difference in worldview. The example presents to affirm that Anishinaabemowin speaking people view the world on a much deeper level, and as such, values, teachings, and guidance are provided directly within the language.

\section{Value Development - Ishpendaagokin}

In his book, Hart (2002) referenced nine value categories consistent across Aboriginal cultures, these included: vision/wholeness, spirit-centered, respect/harmony, kindness, honesty/integrity, sharing, strength, bravery/courage, wisdom, and respect/humility. This is consistent with the seven sacred grandfather teachings of the Anishinaabe: wisdom, love, respect, bravery, honesty, humility, and truth. Wisdom - nibwaakaaawin gikensaasowin is to acknowledge the opportunity to learn in every moment, to be reflective and to seek to extend knowledge and understanding. Love - zaagi-idiwin - zheewenidiwin is to care and cooperate well with others. Love is working toward harmony through kindness and sharing. Respect - manaazodiwin - ozhibwaadenidiwin is to maintain high standards of conduct that provides safety for the dignity, individuality, and rights of every living thing. Bravery - zoongide'ewin is to face adversity with integrity and courage by maintaining a strong sense of self and confidence in one's abilities and character. Honesty - gwekwaadiziwin is to be truthful, sincere, and fair through all circumstances. Humility - dibasendizowin nookaadiziwin is to be modest, respectful, and sensitive in relation to all living things, and 
to know one's status in all of creation. Truth dibasendisowin - nookaadiziwin is to be genuine and true and know human development as it related to all seven teaching (Weechi-it-te-win Family Services, 1999).

Hart (2002) identifies how sharing, respect and spirituality are values especially helpful in attaining wellness or mino-pimatisiwin. Sharing is a value that facilitates equality and democracy within a system; sharing demonstrates that every person is considered valuable. Sacred knowledge, life experiences, and food are shared in order for people to nurture one another. Sharing eliminates the occurrence of greed, individualism, and conflict within a culture. Respect is a value that pertains to treating others with honor, noninterference, and non-judgment. Respect allows the child to see him or herself as an equal part of creation, no better, or no less than every other part of creation. The value of spirituality comes with the understanding that all things have a spirit and are viewed within a spiritual context; this includes healing.

Cultural structure is weaved together through the implementation of customs and traditions as well as rituals and ceremonies. Custom refers to "a practice so long established that it has the force of law" (Dictionary, 2011, p.1). An example of a cultural custom in Aboriginal culture is the offering of tobacco or a gift when asking for knowledge or help. A custom is a universal idea generally congruent among many nations. Traditions are "the handing down of statements, beliefs, legends, customs, information, etc., from generation to generation, especially by word of mouth or by practice" (Dictionary, 2011, p.1) . Examples of traditions are legends, hunting, and craft-making practices. Traditions will vary within nations, communities, and families. An example of the difference between customs and traditions is that it is customary for a nation to have a clan system of government; however, what clan animals are represented and how these are passed will vary based on tradition. A ritual is "an established or prescribed procedure for a religious or other rite" (Dictionary, 2011, p.1). Rituals will also vary between tribes, communities, and families because these are based on tradition. Ceremonies are "the formal activities conducted on some solemn or important public or state occasion" (Dictionary, 2011, p.1). Ceremonies are also based on tradition and will vary to some degree among nations, communities, and families; however, the custom driving the ceremony like marriage, puberty, healing remains the same.

\section{Natural Protective Network Principle - Inaadiziwin}

Fundamental beliefs and customs that apply to children are similar across all North American Aboriginal populations as recorded through early observations of Native American life (Blanchard \& Barsh, 1980). First, children are viewed as a sacred gift and are looked on as an integral part of the family, community, and Nation.

Within this framework, the concept of children as property is foreign. A child has the right by virtue of birth to develop within the context of his or her culture and with the companionship of people through which the strongest definition of self can be formed (Blanchard \& Barsh, 1980, p. 351).

Another such belief is that the child's life begins before conception, this is called manidoo miigiwe bimaadiziwin. Aboriginal people have Creation stories, which suggest we were spirits before we were human, and that our time on this earth is one of having a human experience. This suggests that once we leave this world we will return to the original spirit we once were. While the child is here on turtle island, the natural protective network or inaadiziwin is activated for the child (Simard, 2009). Inaadiziwin is based on the principal that children are placed at the centre of community life and they "in a very real sense represent the renewal and preservation of life" (Blanchard \& Barsh, 1980, p. 350). Aboriginal children are born into a natural protective network of care inaadiziwin including a biological family, an extended family, a clan family, a community, and Nation. The child is provided with instant 
relationships and an inherent network of support (Blanchard, et. al., 1980; Simard 2009). "It is within this interlocking network of support and interdependence that children develop competencies and learn what is expected" (Blanchard et. al., 1980, p. 351). This traditional process facilitates the child's relationships with other people, the spirits, and the world. This inherent set of relationships allows the child to become both a student and a teacher during his or her childhood (Blanchard, et. al., 1980). The natural protective network or inaadiziwin provides children with a concrete understanding of community due to their,

\begin{abstract}
close contact with many people who praise, advise, guide, urge, warn, scold, but most important, respect children [...], throughout the child's development, the connections between everyday activity and the meaning of life are made clear so they can be understood by the child (Blanchard, et. al., p. 351).
\end{abstract}

This cognitive process makes sense to children because it is congruent to their community life experience and is relevant to their place within that system of care (Blanchard, et. al., 1980).

\section{Cultural Attachment - Wiidamaagowiziwinan}

Cultural attachment is a philosophy, which encapsulates how an individual bonds to his or her culture. Cultural attachment creates a direct spiritual force, where the bond begins, develops, and evolves for the individual. In Anishinaabemowin, cultural attachment is expressed as wiidamaagowiziwinan. This means the deep connection between the individual and their spiritual connection to their Creator through his or her access to cultural structure. Cultural attachment is a life-giving philosophy, as it instills life force energy into an individual.

Cultural attachment has remained in Aboriginal worldview because as Aboriginal people there exists the genetic memory of the ancestors, this is called gichi Anishinaabe aadizokaan(an) / gagiikwewewin(an). This genetic memory is the spirit of Aboriginal people. Cultural attachment is built on the principle that cultural memory is carried in an Aboriginal's DNA. This cultural memory becomes active or alive, and inspires connection to the spirit. Many people feared that historical effect and colonization has eroded the cultural memory of the Aboriginal people, but they cannot be further from the truth. The truth is that cultural memory, connection to that memory, and its subsequent cultural attachment has never left the people, it has only waited to be awakened.

Simard (2009) discussed cultural attachment theory as a champion to culturally restorative practice. Originally, attachment theory was deconstructed from an Aboriginal perspective, wherein, philosophies, theories, application, research, and practice was analyzed through the lens of Aboriginal worldview. The intent was to understand this key children's mental health and child welfare driver and its impact on Aboriginal children and youth. The result of this analysis was the development of a new attachment theory called cultural attachment theory. The conceptual framework was not to discredit or minimize attachment theory but to say, attachment theory by itself has not worked for Aboriginal people. Cultural attachment theory is built upon an existing framework, which supports Aboriginal cultural structure. Cultural attachment can reinforce cultural structure processes in the healthy development of Aboriginal children. Cultural attachment theory seeks to secure knowledge of family, extended family, community, and Nation and their relationship to each other and the world. Cultural attachment theory is the natural resiliencies, which exist within the Aboriginal cultural structures, which are supported by the roles inherent in raising a child of the Creator. Cultural attachment theory provides an Aboriginal child with the ability to have a secure base in which he or she can explore the world. More specifically, cultural attachment theory provides the individual with cultural support, via the structures to successful transition to adulthood. Cultural 
attachment theory promotes the affectionate bond between a child and his family that endures over time and space throughout one's lifetime. Further, cultural attachment theory in application is the systematic embracing of the Aboriginal culture and matching of services to meet the cultural needs of the Anishinaabe child.

\section{Cultural Identity Formation}

The next phase in the development of the spirit is cultural identity formation. This section will discuss what the literature depicts on Aboriginal/ Indigenous identity development. Further, it will offer the opportunity for Aboriginal children to hold their head high despite the dynamic of colonization (Ball \& Simpkins, 2004). Cultural identity formation refers to a person's ability to self identify with a particular culture or Nation. Cultural identity is "a person's affiliations with a specific group, qualitative classifications of membership and although it is usually a self perception, in some cases it can be assigned by others [...], ethnic groups, self identification, personal traits" (Oetting, Swaim, \& Chairella, 1998, p. 131). Cultural identity is development by the social learning concepts, which exists within specific cultural groups (Oetting, et. al., 1998). Cultural identity includes the person's attachment to cultural values, teachings, language, sacred traditions, territory, shared history, and learned wisdom (Peroff, 1997).

Weaver (2001) explains three facets of Aboriginal Identity including self-identification, community identification and external identification. She also explains that the premise of the article is based on cultural identify as revealed through values, beliefs, and worldview (Weaver, 2001). Weaver upholds that identity does not exist until it is constructed; therefore, prior to European contact there was no Aboriginal identity but rather tribal groups based their identities in relation to distinctions between other groups. Other aspects that form identity include recognition, absence of recognition, and misrecognition by others; absence of recognition and mis-recognition can be forms of oppression, especially if applied in a systemic manner (Weaver, 2001). Identity is also multi-layered and situational depending on whom the individual is relating to at the point in time. For example a Native person may be turtle clan when relating to others in his or her tribe, Ojibwe when relating to other Native people, and First Nation when relating to non-Natives (Weaver, 2001).

Self-identification is explained as being formed by self-perception.

Cultural identity is not static; rather, it progresses through developmental stages during which an individual has a changing sense of who he or she is, perhaps leading to a rediscovered sense of being Native (Weaver, 2001, p. 244).

The development of cultural identity is a process that progresses through understanding and awareness across the lifespan. Community identification is based on the premise that
Aboriginal identity is connected to a sense of peoplehood inseparably linked to sacred traditions, traditional homelands, and a shared history as Aboriginal people [...], the sense of membership in a community is so integrally linked to a sense of identity that Native people often identify themselves by their reservations or tribal communities (Weaver, 2001, p. 245).

It is important to understand that Aboriginal people have strong connections to their homeland to the extent that they may experience significant problems when they are away from home that can only be remedied by returning to their traditional homeland for ceremony and/or connection (Weaver, 2001). External identification pertains to the effects of non-Native definitions of Aboriginal identity. Specifically, the role that federal policy has played in defining who is Native and who is not and what social and economic roles Native people should take on (Allotment Act). External identification is also affected by the current Native American stereotypes that continue to exist in dominant society today (Weaver, 2001). 
According to Weaver (2001), the facets of identity can interact in a conducive or conflicting manner. It may be difficult for those re-discovering their self-identification but have lost connection or have no knowledge of their community. Such people may have experienced inter-racial adoption, foster care, or boarding school. Interchangeably there may be those who have strong community connections but little cultural knowledge. Once again, such people may be children of those who have experienced some type of disconnection such as foster care. External identification is not based on reason.

While it makes sense that a community should define its members, it does not make sense for an external entity to define Aboriginal people. It is not up to the federal government or any dominant society institution to pass judgment on the validity of any individual's claim to an Aboriginal identity" (Weaver, 2001, p. 248).

Weaver (2001) goes on to demonstrate how external identification has led to internalized oppression among Native populations.

Aboriginal identity cannot be measured by one method alone. Assessment tools are designed to measure or assess cultural identity along a continuum; however, many of these measures are based on "measures of acculturation into dominant society" (Weaver, 2001, p. 248). Weaver (2001) cites Zimmerman whom developed an assessment tool that conversely measures enculturation, which is more reflective of cultural growth across the lifespan.

Another article described in the literature on identity, discussed the disparities and mental health issues facing youth from culturally diverse backgrounds (Pumariega, Rogers, \& Rothe, 2005). One alarming disparity is the fact that Native American youth have the highest suicide rates among the adolescents in the U.S.( Pumariega, et. al., 2005). The authors discussed how culture influences child development.

Cultural values help define childrearing practices and developmental norms (including behaviorally and emotionally) and expectations for such landmarks as toilet training, when to leave a child unsupervised, readiness of expression of sexuality and intimacy, and readiness to leave the parental home (Pumariega, et. al., 2005, p.540).

Culture plays a major role in determining family, gender, and occupational roles; it also greatly influences interpersonal communication within the family and community. The developmental tasks of minority youth are far more challenging, as these youth must adapt to at least two cultures; their minority culture and the culture of larger society.

This implies the development of knowledge, skills, and understanding in at least two cultures; while the youth retains his/her original cultural identity, they become adept at interfacing with the mainstream culture (Pumariega et. al., 2005, p. 541).

Therefore, minority youth are challenged from school age to incorporate various cultural perspectives. As a result, identity for Aboriginal children must be considered with the understanding of adaption to worldviews; however, the core of Aboriginal identity must continue to be developed.

In cultural restorative practice model, cultural identity is a result of cultural attachment to cultural structures, thereby creating the spiritual essence of an individual. Cultural identity is the foundation from which all other domains of development will grow this will include physical - inamanji'owin, emotional - naanaagajiinendamowin, social - maawanji'idiwin, and cognitive - waawaanendamowin. Cultural identity begins with understanding of who you are and what your sacred purpose is while you are here on turtle island. It is living with spiritual purpose grounded in the cultural structure of the Aboriginal nation. Spiritual purpose in one's life does not mean dogmatic structure, what it means is that the individual is grounded in the values of 
the culture and can live in sacred harmony with oneself, his or her relations, and the world.

Cultural identity development can be restored at any age because cultural identity is helping someone return to his or her own spirit. The most important part of cultural identity development is ensuring the opportunities for cultural development exist within a community or a service structure. The opportunities need to allow for the expression, the practice, and the experience of cultural structures, such as sweatlodge ceremonies, long house ceremonies, pipe ceremonies, drumming groups or any cultural activity that enriches the spirit. Cultural structures can reinforce the cultural identity development because cultural identity is being equipped with the knowledge and skills within a young person's cultural background.

Cultural identity cannot be developed without all the factors being included. These factors are the understanding of colonial process, and its subsequent impact on a Nation of people. The explanation of the link between historical effect and present day calamities need to be acknowledged. Cultural shame or cultural selfloathing is a direct result of the unresolved historical effect; as such, a grief/healing process needs to be championed by the worldview of the Aboriginal person. Further, this worldview and cultural structures need to be offered as a mode of healing for the Aboriginal child and youth. Elders validate children and youth's experience of the dysfunction of historical effect (Weechiit-te-win Family Services, 2005). The elder's say this has created a wedge between the child and the cultural structure, and as such, the reintroduction needs to be gradual (Weechi-it-te-win Family Services, 2005). However, the elders have also acknowledge the power of cultural structures to heal the child, youth, family, and community (Weechi-it-te-win Family Services, 2005).

\section{Relationship - Gidinawemaaganinaanig}

Relationships are secured through the natural protective network principle - inaadiziwin. Relationships begin with the family, the extended family, the community, and the nation. Relationships also exist through the wholistic definition of family. Simard (2009) discussed many definitions of family that could be incorporated into the relational system - gizhewaadiziwinan. The definition of family was first researched by Jourdain and was published in Simard (2009), they are described as follows:

Nuclear family: Immediate family, mom, dad, siblings

Extended family: Aunties and Uncles on Paternal or Maternal sides, cousins, second cousins, maternal family lineage and paternal family lineage

Community family: This is the membership of a First Nation community; Nation family: These are the members, who exist within a treaty. For example Treaty \#3 is a nation and those members within this area are in fact family

Nationhood family: These are all the members of the Anishinaabe family, regardless of jurisdiction, provincial territories, or countries. It is all Anishinaabe

Clan family: There are significant teachings on clan and clan family which details the innate relationship to each other through our spiritual clan protector

Cultural family: The cultural family is linked to the ceremonial practices of the Anishinaabe. It is also the support within these circles of ceremonial activities" (Jourdain, 2006, in Simard, 2009, p. 56).

Each relational layer - gizhewaadiziwinan within the natural protective network - inaadiziwin, is established to strengthen and reinforce the healthy 
transition points of Aboriginal people. If the Aboriginal child has a solid foundation from which to explore the world and know where he or she fit within it, the Aboriginal child can achieve greatness (Weechi-it-te-win Family Services, 1995).

\section{Task Completion \\ - Gashkitwaawin/ gashkichigewin}

Gashkitwaawin / gashkichigewin is when an individual accomplishes a developmental task. Measuring task completion of the spirit is shown through the life in the eyes of an Aboriginal child and youth. This means an Aboriginal child and youth feels good about themselves. They understand that they are protected, loved, and cared for within their relational layers gizhewaadiziwinan of the natural protective network principle inaadiziwin. Aboriginal children and youth have cultural pride and can show leadership through various social engagements. Task completion means Aboriginal children have problem solving skills, healthy decision making, and are grounded in the spirit in the face of adversity. They are competent in cultural activities, but they are equally competent in the mainstream world. They are able to function in society regardless of the systematic racism that exists, and they in their own way take on social advocacy education or roles. An Aboriginal child and youth will have an understanding of his or her own identity and have self worth because of that identity. Task completion of the spirit uses context, worldview, cultural structure, cultural attachment, identity, and relational development to create these types of outcomes for Aboriginal children and youth.

\section{Models - Aabijichigan(an)/ aabijichigan(ag)}

The following models are developed by Aboriginal people and were founded on Indigenous knowledge. The models presented are a small sample of a rapidly growing resource. These models come from Aboriginal worldview and can be used in assessment and service provision for Aboriginal children and youth. Although these models are not yet considered "evidence based" through western standards, the models are the practice-based models on an ancient systems of knowledge that resonates within Aboriginal populations. These models can complement or even replace western models in providing services to Aboriginal children and youth. Models require cultural diversity strategies, one size does not fit all in Aboriginal worldview, you must allow for diversity that exists between Nations, between communities, and between families.

\section{Cultural Developmental Milestones Principles}

The cultural developmental milestones principle was documented by Simard (2009) but was developed by Jourdain (2005). The model is based on indigenous knowledge and traditional teachings of Ojibwe elders. The model identifies the four hills of life including: Abinoojiiwin or childhood, Oshkinigiwin or youthhood, Nitawigiwin or adulthood, and Kitisiwin or elderhood (Jourdain, 2005, in Simard, 2009). Within the four hills of life are psycho-spiritual tasks and cultural ceremonies. According to the model, if these tasks and ceremonies are not accomplished there are psycho-spiritual consequences.

Abinoojiwin occurs from ages 0.11 years old. During this time, the child must develop an identity and trusting relationships. The ceremonies that facilitate task completion during Abinoojiwin are: Welcoming, Naming, Clan Identity/Walk-out Ceremony (Jourdain, 2005, in Simard, 2009). If a child does not accomplish these tasks he or she will experience an identity crisis and have difficulty trusting others. Oshkinigiwin occurs from ages 12 - 15 (Jourdain, 2005, in Simard, 2009). Youth this age must learn to understand their physical, mental, emotional, and spiritual needs. They must also learn essential life skills. 
An instrumental task for youth this age is the attainment of a vision. The youth is provided with guidance for a fasting ceremony during this time in his or her life. The youth may also be initiated into the Medicine Lodge or midewewin. If the youth does not complete psycho-spiritual tasks of Oshkinigiwin they may experience physical aggression, emotional and mental arrest, inability to cope, wondering behavior, and spiritual emptiness. Nitawigiwin occurs from ages 15 - 50 years old. Nitawigiwin. The tasks of adulthood are learning independence, procreation and parenthood, and leadership skills. Adults in this age group participate in traditional ceremonies and learn to conduct ceremonies and healing. If the tasks are not achieved, the adult can experience dependency or addiction, lack of selfconfidence, and the inability to care for others. The task of Elderhood or kitisiwin is to become a teacher and people in this age group are asked to take on a leadership role in the ceremonies. If the tasks of Elderhood are not achieved, the person will have difficulty sharing and cooperating and may not have a sense of fulfillment.

\section{Child Rearing Practices}

The data contained within this section on child rearing practices was gathered through a discussion with Weechi-it-te-win Family Services ogitchitaakwewag - female elders. The document Traditional Childcare Practices: Raising our Children the Anishinaabe Way (1995) identifies key cultural developmental drivers for Anishinaabe children. The traditional teachings on childcare practices began with the elders who have lived and breathed these teaching throughout their lives.

The second source of information is from Raising Healthy Anishinaabeg Children (University of Minnesota Duluth, 2011). This was a three-year project in which elders were consulted through focus groups to identify key developmental assets for raising healthy children ages 12 - 18. The project is a resource for professionals and family members to gain the elders' perspective in raising healthy Anishinaabeg children. Through focus group consultations, these elders stated "healthy Anishinaabeg children make good decisions on their own and apply values to their own lives. They have positive self identification, are comfortable with who they are, are spiritually connected, and are part of an extended family unit and a cultural community" (University of Minnesota Duluth, 2011, http://www.d.umn.edu/sw/cw/anish_ child/index.html).

\section{Principles of Parenting}

Parenting practices developed through these sources of information. Take the concept spirituality, which is a learning process that occurs over the lifespan. There is no set age to teach children about traditional values and beliefs; this is something learned all through life. It is important that children are not forced to adopt a certain belief system. They can be offered many beliefs systems, and the parents should always respect their freedom of choice (Weechi-it-te-win Family Services, 1995).

Special teachings exist for Aboriginal girls and boys. Traditional teachings specific to womanhood should be provided by women. Women cannot provide boys with teachings about manhood; this must be done by men (Weechi-it-te-win Family Services, 1995). One teaching specific to women is regarding their connection and reverence to water. A baby is protected within a system of water while being carried in the woman's womb. This water comes out into the world before the baby and of this women were given a special connection to water. It is believed that women are keepers of the water, and men are the keepers of fire. In Anishinaabe ceremony, a woman will always be called upon to provide a prayer for the sacredness of water.

A child is "taught according to seasons" (Weechi-it-te-win Family Services, 1995, p. 15). There are specific teachings to be provided at certain times of the year. For example, legends are told only during the wintertime and only when there is snow on the ground.

Children are taught to respect everything and everyone, and they are to be encouraged to connect 
with mother earth. Children are to be raised with respect because they will become their parents' caretakers someday.

In Aboriginal society, it is the entire community's responsibility to raise the child by providing direction, supervision, guidance, and discipline. The elders believe that children must learn natural consequences and parents are not to interfere in the child's challenges; instead they are to be supportive, encouraging, and always aware of the sacred gift and responsibility that has been bestowed upon them (Weechi-it-te-win Family Services, 1995).

The position of grandparents in traditional child rearing is to provide knowledge and guidance within a relationship of unconditional love. In Anishinaabe life a female elder is grandmother to all children in the community and had the right to teach and discipline. It was the responsibility of grandparents to teach the children physical tasks such as making food and crafts, but they would also provide the value-based teaching that go with each task. The grandparents were the story tellers and would often teach by telling a story "about animals, clans, the future, and respect for nature" (Weechi-it-te-win Family Services, 1995, p. 16). Stories are different from legend, which can only be told in the winter. Legend telling was a lesson in listening, learning, problem solving, and spirituality. Sometimes it would take days for a legend to be told from beginning to end and children were to sit up and not fall asleep during story telling time as this was a form of disrespect (Weechi-it-te-win Family Services, 1995).

It is important to note that although ages have been separated into developmental groups, in Anishinaabe life some of these stages overlap, meaning that some teachings and practices continue throughout the entire childhood.

\section{Ages 5 - 8}

For Anishinaabe children ages 5 - 8, life is all about learning, primarily through the Seven Grandfather teachings of wisdom, love, respect, bravery, honesty, humility, and truth. Children in the age group are in the process of developing a value system. The values and lessons that children ages 5 - 8 learn are related to respect. Primarily respect for nature, for other people, elders, and for themselves. At this age, children were primarily taught to respect themselves and everything else around them. Children this age were taught to wake up with the sun and go to sleep when the sun goes down; this was a teaching about respect for nature and for the good spirits that are active during the day. Children this age learned to offer tobacco for everything they take from the earth. They also learned about personal safety and to stay close to home where they can be supervised. Sometimes stories were told or tactics were used to invoke enough fear in children this age to stay away from dangerous areas and to stay close to home (Densmore, 1979). At this age, children are introduced to spiritual teachings such as the importance of their name, clan, and dreams. Children this age would be given regalia, and a ceremony to begin dancing in the pow-wow circle (Weechi-it-te-win Family Services, 1995).

Children ages 5 - 8 were taught through legends and stories given by grandparents and elders. It is believed that legends were an efficient discipline technique, "a legend would be told to the child to help him understand their behavior" (Weechi-it-te-win Family Services, 1995, p. 22). Boys were taught to fish and hunt. At the time of their first kill, the community or family would ensure that a ceremony occurred, which included a feast to honor the animal. Through hunting and fishing, young men were taught to be a "provider" for his future family (Weechi-it-te-win Family Services, 1995).

\section{Ages 9-12}

Teachings become more specific for children ages nine to twelve; the teachings for this age group focused on preparation for puberty or what can be termed rites of passage from childhood to young adulthood. Girls learned to relate to the moon as her grandmother, and they were taught special ceremonies to honor that connection.

In present day Anishinaabe culture, when a girl has her first menstrual cycle she is left alone 
for 10 days under the care and instruction of a female elder or female family members. In some Anishinaabe cultures, the girl must fast with no food or water for four days (Densmore, 1979). She is not to be in the presence of men during this sacred time, out of respect for the power that she carries, which is essentially the ability to be life-giving. According to elder's teachings, the young woman is put on a berry fast for one year in which she is restricted from several activities.

She is not to go swimming during the first summer, cannot pick up or carry a baby, cannot go berry picking or eat berries of any kind, cannot hunt, skin animals or walk over anything (Weechi-it-te-win Family Services, 1995, p. 23).

After the berry fast, there is a feast and ceremony where the young woman can begin to re-engage in activities that were prohibited. The teaching around prohibiting the girl from eating berries and such is to teach her patience and discipline; two qualities believed to help her in her life (Densmore, 1979). Another important puberty teaching for girls is for them to have a set of their own utensils to be used only by them when they are on their moon-time, these usually become part of their personal bundle (Weechi-itte-win Family Services, 1995).

Boys are given very specific teaching during the ages of $9 \cdot 12$, which help them to prepare to become men. When a boy's voice begins to change, he is required to fast. They are to go without food or water for four days and three nights. The boy is taken to a sacred spot where he was prepared to fast for his vision. "He wasn't told why he was being put out in the bush, but through his dreams and visions, later in life he will understand the meaning of this ceremony" (Weechi-it-te-win Family Services, 1995, p. 24). It is also important to note, that boys may not receive a vision on their first vision quest; but throughout their lives they have the option to fast for a vision again. Throughout their rites of passage boys are also taught to respect everything, especially woman, and they are taught to become providers by hunting and being competent at making things (Weechi-it-te-win Family Services, 1995).

\section{Ages 13 -18}

During the teen years, ages $13 \cdot 18$, a young person's teachings become more concrete. The teachings continue during rites of passage or puberty. It was expected that youth this age show respect for all things. Young women are taught that they carry a powerful spiritual force that comes from their moon time and that they could do harm to others if they do not respect themselves. Young men are taught to become responsible providers for their families (Weechi-it-te-win Family Services, 1995). The Elders advised that youth ages $12 \cdot 18$ need the support and active involvement of their family, extended family and community; therefore, parents should organize their time around their child (University of Minnesota Duluth, 2011). To support Anishinaabe youth, parents must be home for their children, pay attention to them, and learn to communicate with them. Elders agree that youth should spend quality time with their grandparents and other elders to learn about the traditional ways and to visit with one another (University of Minnesota Duluth, 2011).

Youth who are empowered, know they are valued and that they will have opportunities to learn from their mistakes. They are praised often and treated with respect. "These activities are rehearsals for real life activities they will face" (University of Minnesota Duluth, 2011, p. 1). Youth must be praised but also allowed to make mistakes and learn to "get back up after they fall down" (University of Minnesota Duluth, 2011, p. 1). The elders advised that it is important for children in this age group to have knowledge of their culture "Those children that keep their culture do the best at staying healthy" (University of Minnesota Duluth, 2011, p. 1).

To ensure Anishinaabe youth use their time constructively, the elders advise parents to limit television and provide opportunities for them to be close to nature. Being close to nature is where they can learn about medicines and survival, these are valuable teachings that the youth will 
use throughout their lives. In order for youth to develop a commitment to learning, they must have positive relationships with their school and feel good about who they are within that system. The elders recommend creating opportunities for youth to learn their Native language because the "good life" or "mino-bimadiziwin" is within the language (University of Minnesota Duluth, 2011).

For Anishinaabe youth, instilling positive values requires a grounding or connection to their cultural values and community. This connection provides a sense of belonging and security. The elders believe that positive values such as humility, sharing, respect, and humor must be modeled by the parents. Youth ages $12 \cdot 18$ should have their Anishinaabe name and know their clan they belong to, this helps the young person to know who they are so they can move forward in fulfilling his or her purpose in life. Being socially competent will allow youth to make good decisions and practice healthy conflict resolution. The Elders say that in order for this to occur, youth must be familiar with their spiritual practices and ceremonies. As the young person become familiar with his or her own cultural practices, he or she will be able to appreciate his or her own culture as well as that of others (University of Minnesota Duluth, 2011). Last, the elders believe that Anishinaabe youth require their parents to be role models of healthy behavior, provide good supervision, and provide stable consistent parenting. Youth require attention just like smaller children; they also require routines, rules, chores, and other expectations. This is a part of preparing the youth for adulthood (University of Minnesota Duluth, 2011).

\section{The Cree Medicine Wheel Guide for Healing First Nations}

The Cree Medicine Wheel Guide for Healing First Nations is a wholistic social work treatment model that can be applied at the individual, family, and community level. The underlying philosophy of the model signifies spirituality, achievement of wellness, and wholeness through finding balance. The model is grounded in the idea of finding balance and harmony in relationship with all of creation; thus, someone who is out of balance (addiction, low self-esteem, violence) can be healed by incorporating Medicine Wheel teachings into his or her life. This model is supported by social works current trend to look outside the box and explore alternative methods of helping Aboriginal people (Nabigon and Mawhiney in Turner, 1996).

The Cree Medicine Wheel is based on two basic assumptions. The first is that spiritual life force is always present and all human beings require spiritual assistance in some manner (Nabigon and Mawhiney, in Turner, 1996).

... Cree ways of helping offer us ways to balance our inner selves by listening to ourselves, our surroundings, and others. When we listen to our inner self, we get in touch with our inner spiritual fire (Nabigon and Mawhiney, in Turner, 1996, p. 21).

The second assumption denotes that every person has an external and inner self; both require equal attention. Feeding the spirit is as equally important as feeding the body and both must be attended to in a caring manner.

The Cree Medicine Wheel is divided into four quadrants representing various teachings. It also includes layers of circles that begin at the centre and move outwards, which represent various levels of being; this is referred to as "the hub" (Nabigon and Mawhiney in Turner, 1996, p. 22). The outer circle represents the negative aspects within each quadrant and the inner circle represents the positive sides of being. The inner most circle represent the person who is part of the creator and all creation (Nabigon and Mawhiney in Turner, 1996).

Teachings within each of the directions that can be related to cultural attachment. In order for children not to feel inferior, powerless and victimized, it is important for them to "feel they have some power of choice over their own lives as they grow up" (Nabigon and Mawhiney in Turner, 1996, p. 22). Cree teachings emphasize the concepts of self-empowerments and self- 
responsibility; therefore, success is defined and measured by the individual based on his or her own goals. The Cree Medicine Wheel emphasizes the importance of being still and listening to the self. Development of the core is essential to successful developmental transitions.

"The hub is useful in showing the interconnectedness of people in their external world, which includes ancestors, family, friends, community and natural environment" (Nabigon and Mawhiney in Turner, 1996, p. 26). The important values that form the Cree Approach, includes the connection to ancestors is the belief that their actions have influence on the current life process of each individual in the present. Each individual's actions will have direct implications for the next seven generations. Further, the value is in becoming close to nature and observing the animal world. The animal world teaches life values such as kindness, honesty, respect and how to conduct oneself in relation to another. Another important value within this model is that everything is viewed as a spirit (Nabigon and Mawhiney in Turner, 1996).

\section{Native Self Actualization Assessment Placement}

The Native Self Actualization Assessment Placement was developed from the High Fidelity Wraparound model that evolved from John Brown and associates of the well-known Brownsdale programs (Stone Brown, 2008). Stone Brown (2008) developed the model from a needs assessment conducted on the urban Aboriginal population in Denver Colorado. The Native Self Actualization model is the first step in implementing the high fidelity wraparound process for families in crisis (Stone Brown, 2008). This model essentially assesses the level of enculturation within an individual or family.

The primary function of the Native SelfActualization model is to determine the worldview of each member of a family (Stone Brown, 2008). It is based on eight domains from which four different worldviews can be determined. This determination is done by the client. Each domain is based on a continuum that moves from a fully western or contemporary worldview to a fully traditional worldview.

Four aspects of worldview make up the continuum within each domain. The first worldview is a fully traditional worldview meaning that person's belief system, practices, teachings, language, and thought process are based on Aboriginal teachings. First worldview people are very attached to culture and the majority of their social lives happen within their own cultural networks. First worldview people will prefer to use their traditional medicines or healers to deal with health issues. Second worldview is a traditional/ contemporary worldview, which means that the person has a "predominantly traditional worldview that is mixed with contemporary" (Stone Brown, p. 12). The third worldview or "Contemporary / Traditional" is a transitional worldview like the second worldview; however, third worldview is predominantly a contemporary worldview that moves toward traditional. The fourth worldview is a fully contemporary worldview in which the person's beliefs systems are non-traditional where thinking is linear, language is non-native and there is an apparent detachment from culture (Stone Brown, 2008). The assessment tool is broken down into eight domains: spirituality, social/ recreation, learning, family, food, time, language, and attachment to culture.

\section{Relational Worldview Model}

Terry Cross developed the Relational Worldview Model. Relational Worldview is Indigenous knowledge. It is based on the concept that problems are a product of imbalance; therefore, problems must be viewed in light of all related variables, including spiritual forces, and interventions must be geared toward regaining balance (Cross, 2010). Unlike western models, the Relational worldview model does not look for one problem and one intervention; the person is treated in a wholistic manner and various interventions occur. 
The model can be used for assessing family problems and is demonstrated through a four quadrant circle. The four quadrants of context, mind, body, and spirit are realms of being that are constantly interacting to bring about balance and harmony. When assessing Aboriginal families, everything must be looked at within context.

The context within which Indian families function is filled with strength-producing or harmonizing resources. Oppression, for all its damage to us, creates an environment where survival skills are developed and sharpened (Cross, 2010, p. 3).

Aboriginal people have systems within their families and communities, which are interdependent and it is within the context of these systems that Aboriginal people find their identity. The second quadrant includes thoughts and emotional processes; it includes the ways in which Aboriginal people learn to cope with the world through listening and sharing with one another. The third quadrant includes the physical self, gender, health level and how well the body is being cared for. When applying the third quadrant to a family, it refers to the roles and structure of the kinship network and how the family is sustained within this system. The fourth quadrant refers to both positive and negative spiritual influences. The positive practices are those actions that bring about positive spiritual outcomes; whereas, the negative practices are beliefs that limit or cause people to engage in negative spiritual behavior (Cross, 2010).

The Relational worldview model considers all four quadrants and is based on the assumption that the system itself naturally seeks balance and is therefore naturally resilient. The role of the worker is to support the areas of resilience and assist in bringing balance. Aboriginal healers work within this model; they will not exclusively treat the mind, body, or spirit. Instead, they will provide interventions that work with the mind, body, and spirit, which becomes are part of the person's context. Relational worldview model is a traditional practice that has been active in Aboriginal nations for hundreds of years (Cross, 2010).

\section{Western Models}

Western models alone will not work with Aboriginal people, as the principle part of self is not acknowledged by these developmental theories - the spirit. The authors have provided some ideas on how to incorporate the worldview, cultural structure, cultural attachment opportunities into service practice. The service practice at any give agency will need to think about how to systematically address the Aboriginal developmental constructs

\section{WFS BI-CULTURAL PRACTICE}

Elders, Healers, Ceremonies, Sweats,

Shake Tents, Circles, Teachings, etc.
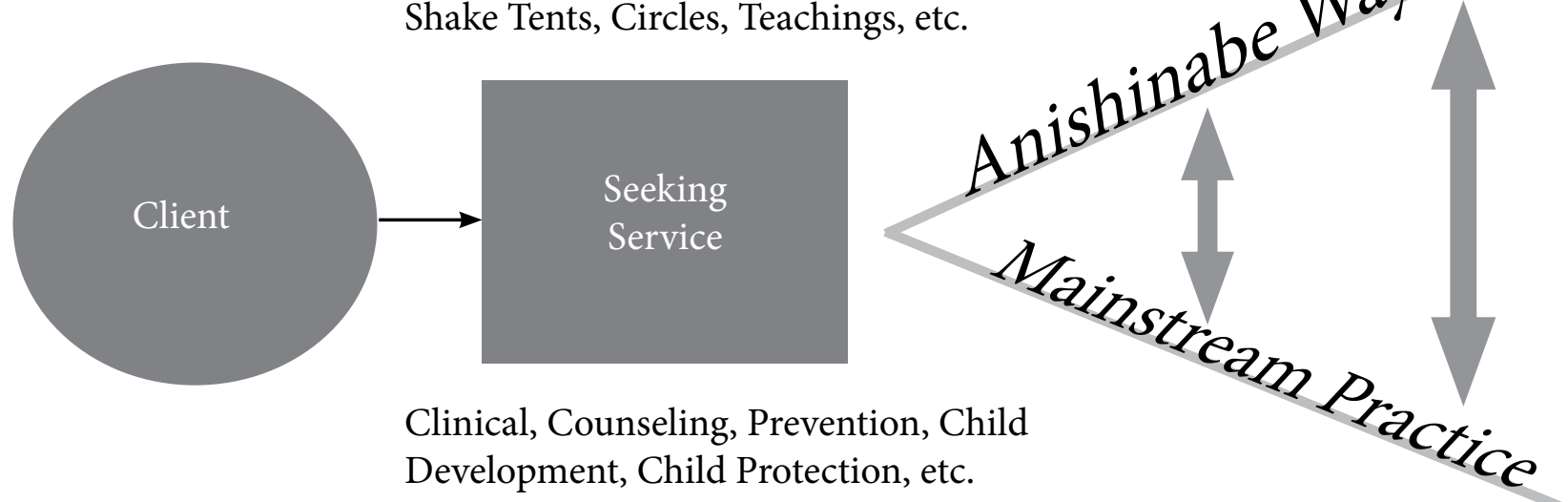

Clinical, Counseling, Prevention, Child Development, Child Protection, etc. 


\section{Western}
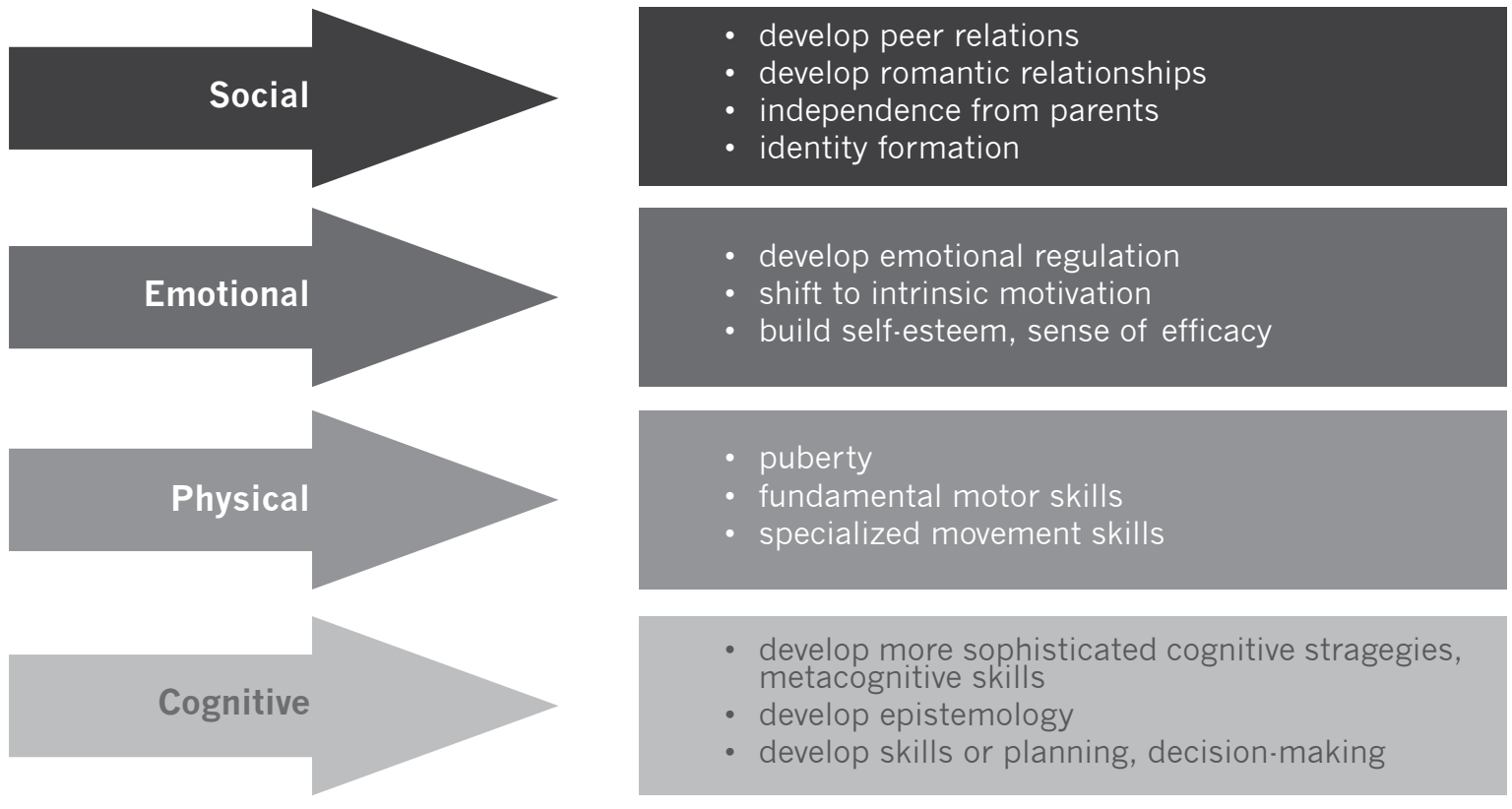

Diagram 3: Ministry of Child and Youth Services (2011)

into their practice. For this, Weechi-it-te-win Family Services has offered their model of bi-cultural practice for consideration (see digram 2 below).

The philosophy of bi-cultural practice is to ensure the client has the best of both worldviews and their subsequent philosophies. Years of practice- based evidence exists for Weechi-it-tewin Family Services, which has evolved this type of services to a strong cultural restorative practice model (Simard, 2009).

Another important part of western models and their incorporation of developmental theories with Aboriginal people are many disconnected views of development throughout the lifetime. At present, there is a multitude of developmental theories leading the way; however, they are not connected into one single entity. In addition they are trajectories for the child, and seen as benchmarks of achievement (see diagram 3 above).

These development trajectories are not, especially different for Aboriginal children and youth, but there is a significant difference that must be recognized in relation to historical context, contemporary issues, access to culturally safe and supportive services, in light of the socioeconomic context. These variables along with the thematic of Aboriginal development need to be included into the developmental framework as a best practice for Aboriginal people. This will allow for Aboriginal children to success with confidence.

The model presented has offered ideas on how to incorporate the spirit into an Aboriginal child's development. Now it is the time to put it together and look at development from a wholistic perspective.

All parts to self are included within this model. First, within the Aboriginal core is the spirit. Second, all other domains are captured as well. These include the social, emotional, physical, and cognitive domain. Further, the diagram offers the contextual variables, which need to be included within any developmental framework for the Aboriginal child (see diagram 4, following page). 


\section{First Peoples Child \& Family Review, Volume 6, Number 1, 2011}

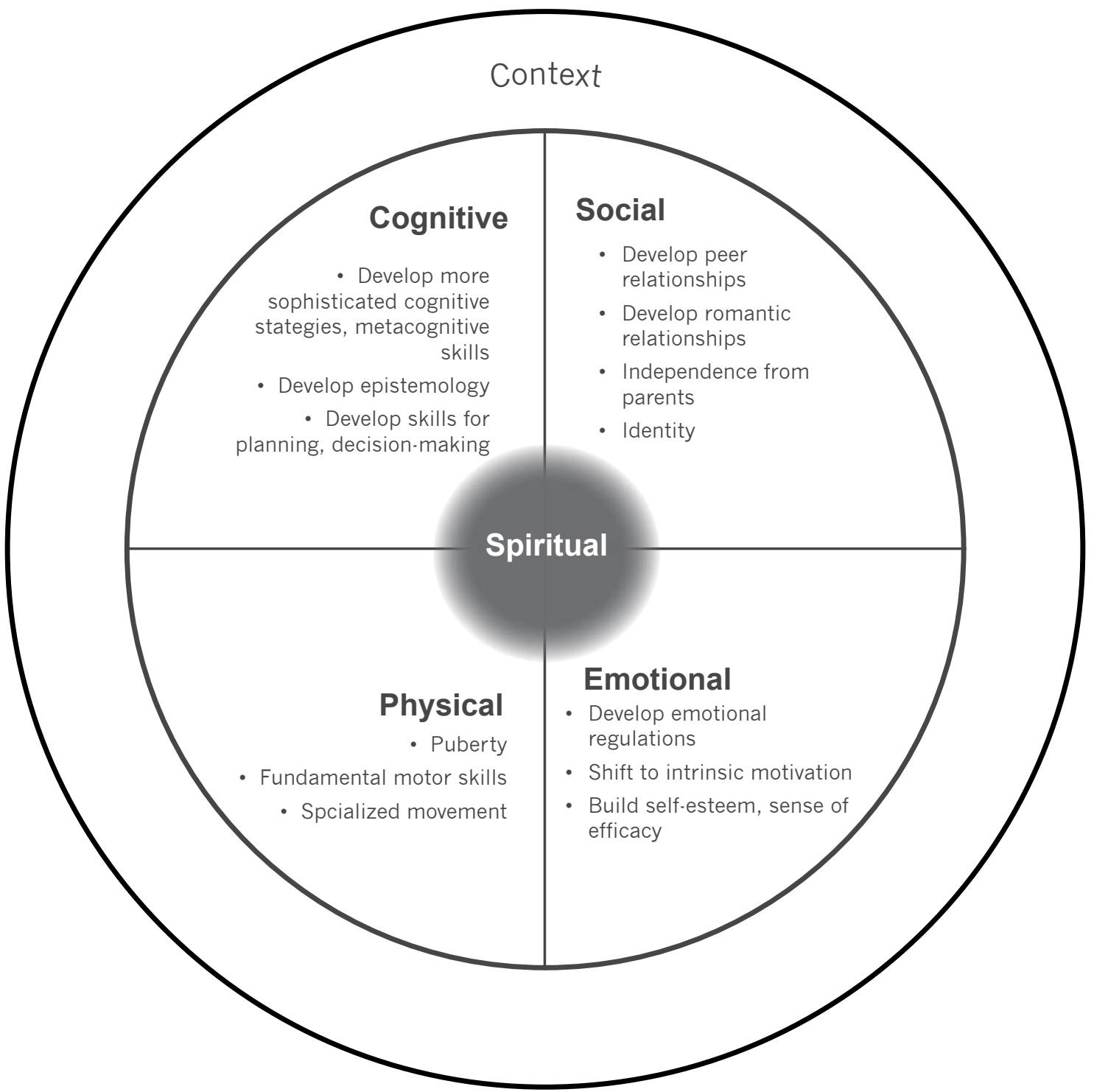

Diagram 4: Aboriginal Worldview on Development, Simard (2011)

\section{Implications for Child and Youth Services}

In working with Aboriginal people, one must remember the long history of colonization and its deep seated effects. Thira (2011) discusses the fourth wave of colonization as the "medical wave, made up of professional caregivers, treatment centres, and others which encourage and provide so-called healing, based on the view of Aboriginal peoples as "sick'” (p. 1). In Thira (2011) framework, if children and youth do not measure up to the standards of development, they are "delayed", but it does not suggest overall there is a problem with societal oppression, which needs to be addressed. 
Conversely, to standardized healing methodologies, this paper demonstrated that Aboriginal knowledge systems are alive and well in the Aboriginal population, and as a result, a shift in policy, practice, regulations, and assessment, warrants consideration. The trend in assessment and service models based on Aboriginal knowledge is a valuable resource for child and youth services in Ontario. Interventions designed by Aboriginal people, and based in Aboriginal knowledge can compliment western models; these interventions can also replace them entirely. With careful research and the application of the OCAP principles - Ownership, Control, Access, and Possession the Aboriginal worldview outlined in the report can be empowered in service delivery systems (First Nation Centre, 2007).

Those professionals in charge of child and youth services in Ontario will have a better understanding of Aboriginal youth in the child welfare, children's mental health, and youth justice systems. The trajectories for development demonstrated in this paper will not only form a framework for assessing development, but influence policy directions that will ensure healthy development for this special population of youth who are over-represented in all systems.

The information revealed the need for policy makers to support the development of cultural interventions, which are meaningful, systematic, and embedded with cultural sustainability. Theoretical and economic support in the areas of culturally safe research and evaluation would prove beneficial to ensuring that cultural restoration frameworks are working effectively for Aboriginal youth. The introduction and maintenance of culturally restorative practices into agency service delivery would not only decrease barriers within the current system but also facilitate human development in the sense that children and youth would be served in a honorable manner.

A recommendation is service providers to consider the development of professional learning communities to discuss cross-cultural work with Aboriginal people. This is to discuss the historical context and learn from Aboriginal people the best practices for helping with the Thematic of Aboriginal development in mind. Professional development programs require a change in operational paradigms. This means moving from a one-time workshop to a professional learning community. Professional learning communities offer: "job embedded learning; an expectation that learning is ongoing and occurs as part of routine work practice; team based action research; learning by doing; learning collectively by working together" (DuFour, DuFour, \& Eaker, 2008, p. 95). Professional learning communities offer more investment in professional development activities, as it promotes collegial support and learning. Further, professionals develop relationships with Aboriginal people, to strengthen and foster positive change for Aboriginal people, and this is a contribution we can make to increase successful transitions for Aboriginal children and youth.

\section{Conclusion}

To implement culturally restorative practice this calls for a shift in paradigms, by voicing the alternatives of child development structure and intent from an Aboriginal worldview. Justification within the collated data presents alternative schemas to developmental models with Aboriginal people. This culturally restorative developmental practice paradigms, includes at the forefront an understanding of Aboriginal history - both positive and negative effects. Negative history begins with the process of colonization whereas; positive history lends its way to a healing process for both cultures along with an understanding of Aboriginal worldview.

Worldview leads into the mechanisms of cultural structure, which exist in all Aboriginal Nations. The application of cultural structure into service practice promotes cultural attachment, which subsequently leads to cultural identity formation. This identity formation leads to relational development, which leads to task accomplishment. Task accomplishment embodies the spiritual part of development, and 
further, leads the way to successful development constructs across other domains. Culturally restorative developmental practice paradigms are the alternative for Aboriginal development.

\section{References}

Absolon, K, (2010). Indigenous wholistic theory: A knowledge set for practice. First Peoples Child \& Family Review, 5, 2, p.74-87. Retrieved on January 8, 2011 from http://www.fncfcs.com/sites/default/ files/online-journal/vol5num2/Absolon_pp74.pdf.

Ball, J., (2004). As if Indigenous knowledge and communities mattered: transformative education in First Nations communities in Canada. American Indian Quarterly, 28(3/4), 454-479. Retrieved November 6, 2010, from Research Library. (Document ID: 825766781).

Ball, J., \& Simpkins, M.A. (2004). The community within the child integration of Indigenous knowledge into First Nations childcare processes and practice. The American Indian Quarterly, 28(3\&4): 480-498.

Battiste, M., (2002). Indigenous Knowledge and pedagogy in First Nation education - A literature review with recommendations: Prepared for the National Working Group on education and the Minister of Indian Affairs Indian and Northern Affairs Canada (INAC). Unpublished government document.

Benton-Banai, E. (1988). The Mishomis Book - the Voice of the Ojibway. Saint Paul: Minnesota: Red School House.

Berrell, M., Gloet, M., (1999). Reflections on the cultural dimensions of educational administration. Journal of Educational Administration and Foundations 1999, 13, 2, p. 10.

Blanchard, E.L. \& Barsh, R.L.. (1980). What is best for tribal children? A response to Fischler. Social Work. 25 (5), p. 350-357.

Bolzman, L., (2009). The advent of child rights on the international scene and the role of the Save the Children International Union 1920 - 45. Refugee Survey Quarterly, 27, 4, 26 - 36.

Cochran, P. A., Marshall, C. A., Garcia-Downing, C., Kendall, E., McCubblin, L., and Gover, M. S., (2008). Indigenous ways of knowing: Implications for participatory research and community. Health Policy and Ethics, 98, (1), p. 22 - 29.

Crooks, C.V., Chiodo, D., \& Thomas, D., (2009). Engaging and empowering Aboriginal youth: A toolkit for service providers. Public Health Agency of Canada.
Cross, T., (2010). Relational Worldview Model. National Indian Child Welfare Association. Retrieved on September 11, 2010 from http://www.nicwa.org/ Relational_Worldview/

Day, P., (2006). Cultural Competence Conference. Unpublished Document. Fort Frances, Ontario Canada.

Densmore, F. Chippewa Customs. St. Paul, Minnesota: Minnesota Historical Society Press, 1979.

Dictionary.com, (2011). Ceremony. Retrieved on January 15, 2011 from http://dictionary.reference. com/browse/ceremony.

Dictionary.com, (2011). Custom. Retrieved on January 15, 2011 from http://dictionary.reference.com/ browse/custom.

Dictionary.com, (2011). Grief. Retrieved on January 15, 2011 from http://dictionary.reference.com/ browse/grief.

Dictionary.com, (2011). Ritual. Retrieved on January 15, 2011 from http://dictionary.reference.com/ browse/ritual.

Dictionary.com, (2011). Tradition. Retrieved on January 15, 2011 from http://dictionary.reference.com/ browse/tradition

Dufour, R., Dufour, R., \& Eaker, R., (2008). Professional learning communities at work. New Insights for Improving Schools, Reston, VA: Solution Tree.

First Nations Centre. (2007). OCAP: Ownership, Control, Access and Possession. Sanctioned by the First Nations Information Governance Committee, Assembly of First Nations. Ottawa: National Aboriginal Health Organization.

Good, A., (2009). Framing American Indians as the "First Americans": Using Critical Multiculturalism to Trouble the Normative American Story. Social Studies Research and Practice, 4, 2, p. 49 - 66.

Grant, D. \& Haynes, D.. (1995). A Developmental Framework for Cultural Competence Training with Children. Social Workin Education, 17 (3), p. 171-182. http://weblinks2.epnet.com/DeliveryPrintSave. asp?tb $=1$ \&_ia $=$ bo $+B_{-}+$shn $=1+d b+a p h j n h+$ retrieved on $1 / 16 / 2006$.

Greenfield P.M., Keller, H., Fuligni, A., Maynard, A. (2003). Cultural Pathways Through Universal Development. Annual Review of Psychology, 54, p. 461-490. Retrieved from Research Library. 


\section{Developing a Culturally Restorative Approach to Aboriginal Child and Youth Development}

Gross, L. W. (2002). The Comic Vision of Anishinaabe Culture and Religion. American Indian Quarterly, 26(3), 436-459. Retrieved from Research Library.

Hart, M.A. (2002). Seeking Mono-Pimatisiwin: An Aboriginal Approach to Helping. Winnipeg, Manitoba: Fernwood Publishing.

Herrmann, K. J., Jr., (1991). Social workers and the United Nations Convention on the Rights of the Child. Social Work, 36, 2,102 - 103.

Mcguire, P.D.. (2008). Restorative Dispute Resolution in Anishinaabe Communities - Restoring Conceptions of Relationships based on Dodem. Research Paper for the National Centre for First Nation Governance. Unpublished manuscript. (check citation)

McKinley, B., Jones, B., \& Maughan E.. (2009). Indigenous Knowledges and the Story of Bean. Harvard Educational Review, (79). http:// proquest.umi.com.ezroxy.apollolibrary.com/ pqdweb? index $=0 \&$ sid $=$ srchmode $=1$. Retrieved $11 / 5 /$ 2010.

Nabigon, H., Mawhiney, A.M.. (1996). Aborignal Theory: A Cree Medicine Wheel Guide for Healing First Nations. In Turner Social Worker Treatment 4th Edition, New York. (Check citation)

Oetting E.R., Swaim R.C., Chiarella M.C., (1998). Factors structure and invariance of the orthogonal cultural identification scale among American Indian and Mexican American youth. Hispanic Journal of Behavioral Sciences, 20, (2). p.131 (24).

Parlee, B., \& O'Neil, J.. (2007). "The Dene Way of Life": Perspectives on Health From Canada's North. Journal of Canadian Studies, 41(3), 112. 133,207. Retrieved December 27, 2010, from Research Library. (Document ID: 1378352801).

Pumariega, A. J., Rogers, K., \& Rothe, E.. (2005). Culturally Competent Systems of Care for Children's Mental Health: Advances and Challenges. Community Mental Health Journal, 41 (5), 539.555.
Simard, E., (2009). Culturally Restorative Child Welfare Practice: A special emphasis on cultural attachment theory. First Peoples Child \& Family Review, 4( 2), 44 . 61. Retrieved on December 12, 2009 from http:// www.fncfcs.com/pubs/vol4num2toc.html.

Simpson, L.R. (2004). Anticolonial strategies for the recovery and maintenance of Indigenous Knowledge. The American Indian Quarterly, 28, 3-4. p.373(12). Retrieved February 15, 2011, from General OneFile via Gale: http://find.galegroup.com.ezproxy.apollolibrary. $\mathrm{com} / \mathrm{gps} /$ start.do?prodld=IPS\&userGroupName= uphoenix.

Sitting Eagle (1993). A series on the Clans of the Anishinaabe (Ojibway) Nation, 1993. Roseau River First Nation Copywrite - Unpublished.

Sitting Eagle (2005). 25th Anniversary Address. Weechiit-te-win Family Services. Unpublished video.

Stairs, A., Bernhard, J .K., (2002). Considerations for evaluating 'good care' in Canadian aboriginal early childhood settings. McGill Journal of Education, 37, 3, p. 309-331.

Stone Brown, S., (2008). Conference Compendium June 08, Post Colonization Native Self Actualization assessment placement: preparing a wraparound evidence based practice for Tribal People, the Denver Indian Family Resource Center, Intersecting Interests: Tribal Knowledge and Research Communities April 16-17, 2008, University of Montana, Conference Compendium June, 2008.

Thira, D., (2011). Beyond the four waves of colonization. Unpublished document. Retrieved on February 2, 2011 from www.swaraja.org/fourwaves.htm.

Tuhiwai - Smith, L., (2002). Decolonizing methodologies: Research and Indigenous peoples. New York New York: St. Martin Press.

University of Minnesota Duluth, (2011). Raising Healthy Anishinaabeg Children. Retrieved on February 19, 2011 from http://www.d.umn.edu/sw/cw/ anish_child/support. 
First Peoples Child \& Family Review, Volume 6, Number 1, 2011

Vollom, J, \& Vollum, T. (1994). Ojibwemowin: The Ojibwe Language (2nd ed.). United States of America: Ojibwe Language Publishing.

Voss, R.W., Douville, V., Soldier A.L. \& Twiss, G.. (1999). Tribal and Shaman-Based Social Work Practice: A Lakota Perspective. Social Work, 44 (3), p. 228-241.

Weaver H. N., (2001). Indigenous Identity: what is it and who really has it? American Indian Quarterly, 25 (2), p 240-255.

Weaver, H., N., (2003). Cultural Competence with First Nations Peoples. In D. Lum (Eds.), Culturally competent practice: A framework for understanding diverse groups and justice issues (2nd ed.) (pp. 197. 126). Canada: Thompson: Brooks/Cole.

Weechi-it-te-win Family Services (1995). Traditional Childcare Practices: Raising our children the Anishinaabe Way. Prepared by: Weechi-it-te-win Family Services by the Fort Frances Governance Team. Unpublished.

Weechi-it-te-win Family Services (2005). Sitting Eagle keynote address (on-line video). http://www.weechi. ca/lawrencehenry.php. 